Société d'histoire de la révolution de 1848 et des

révolutions du XIXe siècle

$47 \mid 2013$

Quel est l'avenir du XIX $X^{\mathrm{e}}$ siècle ?

\title{
Sylvia CHIFFOLEAU, Genèse de la santé publique internationale. De la peste d'Orient à l'OMS
}

Rennes, Presses universitaires de Rennes, 2012, 288 p. ISBN :

978-2-7535-2091-2. 18 euros.

\section{Luc Chantre}

\section{(2) OpenEdition}

Édition électronique

URL : http://journals.openedition.org/rh19/4588

DOI : $10.4000 /$ rh 19.4588

ISSN : $1777-5329$

Éditeur

La Société de 1848

Édition imprimée

Date de publication : 31 décembre 2013

Pagination : 202-204

ISSN : 1265-1354

Référence électronique

Luc Chantre, «Sylvia CHIFFOLEAU, Genèse de la santé publique internationale. De la peste d'Orient à

I'OMS », Revue d'histoire du XIXe siècle [En ligne], 47 | 2013, mis en ligne le 28 janvier 2014, consulté le 22 septembre 2020. URL : http://journals.openedition.org/rh19/4588 ; DOI : https://doi.org/10.4000/ rh19.4588

Ce document a été généré automatiquement le 22 septembre 2020

Tous droits réservés 


\section{Sylvia CHIFFOLEAU, Genèse de la santé publique internationale. De la peste d'Orient à l'OMS}

Rennes, Presses universitaires de Rennes, 2012, 288 p. ISBN :

978-2-7535-2091-2. 18 euros.

\section{Luc Chantre}

\section{RÉFÉRENCE}

Sylvia CHIFFOLEAU, Genèse de la santé publique internationale. De la peste d'Orient à l'OMS, Rennes, Presses universitaires de Rennes, 2012, 288 p. ISBN : 978-2-7535-2091-2.

18 euros.

Dans cet ouvrage, Sylvia Chiffoleau analyse l'évolution des stratégies et politiques sanitaires internationales de la première moitié du $\mathrm{XIX}^{\mathrm{e}}$ siècle à la création de l'Organisation mondiale de la santé (OMS) en 1948. Attentive à retracer les avancées des conférences convoquées entre 1851 et 1938, par les États européens, afin de remédier à la question des épidémies, l'historiographie a trop souvent négligé le théâtre même de ces épidémies, à savoir cet «Orient proche » (p. 14) de l'Égypte et de l'Empire ottoman. C'est pourtant de la prise de conscience, à partir du milieu du XIX ${ }^{\mathrm{e}}$ siècle, d'une «question sanitaire d'Orient»(p.45), marquée par la récurrence des épidémies de peste et de choléra au Moyen-Orient, qu'il faut dater les premiers efforts de coordination internationale en matière de santé publique. Cette "rencontre médicale » (p.19) des deux rives de la Méditerranée doit alors beaucoup aux pouvoirs réformateurs de l'époque (l'Égypte de Muhammad 'Alî, l'Empire ottoman de la période des Tanzîmât), ainsi qu'aux médecins français présents sur place qui ont joué un rôle central comme artisans du transfert et de la circulation du savoir médical. En s'appuyant sur cette volumineuse littérature, l'auteure se livre, tout au long de l'ouvrage, à une relecture culturelle et anthropologique de l'application des normes 
sanitaires et de leur réception dans l'espace musulman. La dimension politique n'est pas pour autant négligée. Dans le prolongement des travaux de Mark Harrison, Sylvia Chiffoleau s'attache à mettre en lumière les rapports de force qui président aux différentes conférences sanitaires ainsi qu'à l'inégalité Nord-Sud qui commence alors à se dessiner, asymétrie observable jusque dans les sources mobilisées (p. 15).

2 L'expansion du commerce en Méditerranée et, plus largement, avec l'Orient, s'est accompagnée dans les faits d'une "stratégie d'externalisation» sanitaire (p.96), consistant à faire porter l'essentiel du coût et du poids des contrôles sur les conseils sanitaires d'Alexandrie et d'Istanbul, du fait de leur proximité supposée avec les foyers épidémiques. Cette politique va trouver son point d'aboutissement dans le projet d'encadrement sanitaire du pèlerinage à La Mecque (hajj). En 1865 en effet, à la faveur du retour des pèlerins en Égypte, le choléra se répand en Méditerranée et gagne l'Europe. Un régime d'exceptionnalité, caractérisé par un renforcement des quarantaines, s'instaure en mer Rouge. L'imposition de la modernité sanitaire devait ainsi paradoxalement passer par la réactivation des anciens lazarets. La brutalité des méthodes employées n'est d'ailleurs pas sans rappeler celle mise en œuvre dans les empires coloniaux, premiers fournisseurs de pèlerins à cette époque, si bien que l'on peut légitimement s'interroger sur leur articulation ${ }^{1}$. Une question reste également en suspens : pourquoi cette violence - le rituel sanitaire imposé aux hajjis dans les lazarets de Tor et de Camaran est décrit dans des pages saisissantes - se concentre-t-elle précisément sur les pèlerins musulmans plus que sur toute autre catégorie de migrants? Une lecture politique du risque sanitaire représenté par le hajj ne s'imposet-elle pas en l'espèce ${ }^{2}$ ?

3 Le moment colonial constitue en effet une étape majeure dans l'évolution des politiques de santé. En exacerbant les positions, l'occupation militaire de l'Égypte par les Britanniques en 1882 a rendu indispensable un compromis entre les puissances européennes. Dans un contexte scientifique marqué par les progrès de la bactériologie, le premier traité international à vocation sanitaire est adopté à Venise en 1892, en attendant la création en 1903 d'un Office international de santé à Paris. Si l'ingérence croissante des puissances européennes dans la région suscite de nombreuses résistances de la part de l'Empire ottoman, le dialogue entre les deux rives n'est pas pour autant rompu. Il se poursuit à travers les conseils sanitaires d'Istanbul et d'Alexandrie, dont l'internationalisation s'accélère et qui constituent, jusqu'à la Grande Guerre, des "courroies de transmission, fragiles mais efficaces» (p.155) en même temps que des espaces privilégiés d'apprentissage.

4 À plus d'un titre la période de l'Entre-deux-guerres, qui clôt l'ouvrage, marque la fin d'une époque. La pandémie de grippe espagnole de 1918-1919 a montré que l'Europe, elle aussi, pouvait être une terre de contagion, au moment même où la peste et le choléra désertaient les lieux saints de l'Islam. L'Europe n'a d'ailleurs plus le monopole de l'édiction des normes, ni de l'expertise sanitaire. Confrontées à l'apparition de nouvelles organisations de santé à vocation universelle, à la disparition programmée des conseils sanitaires d'Istanbul et d'Alexandrie, les puissances européennes doivent également composer avec une nationalisation croissante des pratiques médicales. Enfin, il n'est pas jusqu'à l'hygiène internationale elle-même qui, passées les brutalités de la Grande Guerre, n'ait changé de visage, délaissant son caractère sécuritaire et coercitif, pour évoluer vers davantage d'altruisme et d'humanité. 
Par la richesse de son corpus, son souci permanent de croiser les sources et les regards, l'ouvrage de Sylvia Chiffoleau vient éclairer un aspect méconnu de la mondialisation sanitaire.

\section{NOTES}

1. Cette articulation est mise en valeur dans le récent ouvrage de Saurab Mishra consacré au hajj indien: Saurab Mishra, Pilgrimage, Politics and Pestilence. The Haj from the Indian Subcontinent, 1860-1920, New Dehli, Oxford University Press, 2011.

2. Cf. à ce sujet l'article pionnier de William R. Roff, 'Sanitation and Security. The Imperial Powers and the Nineteenth Century Hajj', Arabian Studies, n 6, 1982, p. 143-160 et, plus récemment, Luc Chantre, «Entre pandémie et panislamisme. L'imaginaire colonial du pèlerinage à La Mecque (1866-1914) », Archives de sciences sociales des religions, n 163, 2013, p. 165-189. 